Supporting Information for

\title{
Thermal and Rheological Analysis of Polystyrene-Grafted Silica Nanocomposite
}

Nazam Sakib ${ }^{\#}$, Yung P. Koh ${ }^{\#}$, Yucheng Huang ${ }^{\S}$, Katrina Irene S. Mongcopa ${ }^{\dagger}$, Amy N. Le ${ }^{\dagger}$, Brian C. Benicewicz ${ }^{\S}$, Ramanan Krishnamoorti ${ }^{\dagger}$ and Sindee L. Simon ${ }^{\# *}$

\# Department of Chemical Engineering, Texas Tech University, Lubbock, TX, 79409, USA.

$\S$ Department of Chemistry and Biochemistry, University of South Carolina, Columbia, South Carolina 29201, USA.

† Department of Chemical and Biomolecular Engineering, University of Houston, Houston, TX 77204, USA.

*corresponding author. E-mail: sindee.simon@ttu.edu

\section{Thermogravimetric Analysis and Small-Angle X-Ray Scattering}

The thermogravimetric analysis (TGA) of PNC-35k, shown in Figure S1, is performed using a TGA Q500 from TA instruments under $\mathrm{N}_{2}$ atmosphere on heating at $10 \mathrm{~K} / \mathrm{min}$ from 25 to 800 ${ }^{\circ} \mathrm{C}$. The TGA of PNC-112k, shown in Figure S2, is performed using a Mettler Toledo TGA 2 under air atmosphere on heating at $1 \mathrm{~K} / \mathrm{min}$ from 25 to $650^{\circ} \mathrm{C}$. Small angle $\mathrm{x}$-ray scattering (SAXS) of PNC-35k, shown in Figure S3, is performed under vacuum using a Rigaku MicroMax-007HF high-intensity microfocus rotating anode x-ray generator. A small mass of sample is secured onto the sample stage with a silver behenate sticker. Data are obtained for $\mathrm{q}$ values of 0.01 to $0.10 \mathrm{~A}^{-1}$.

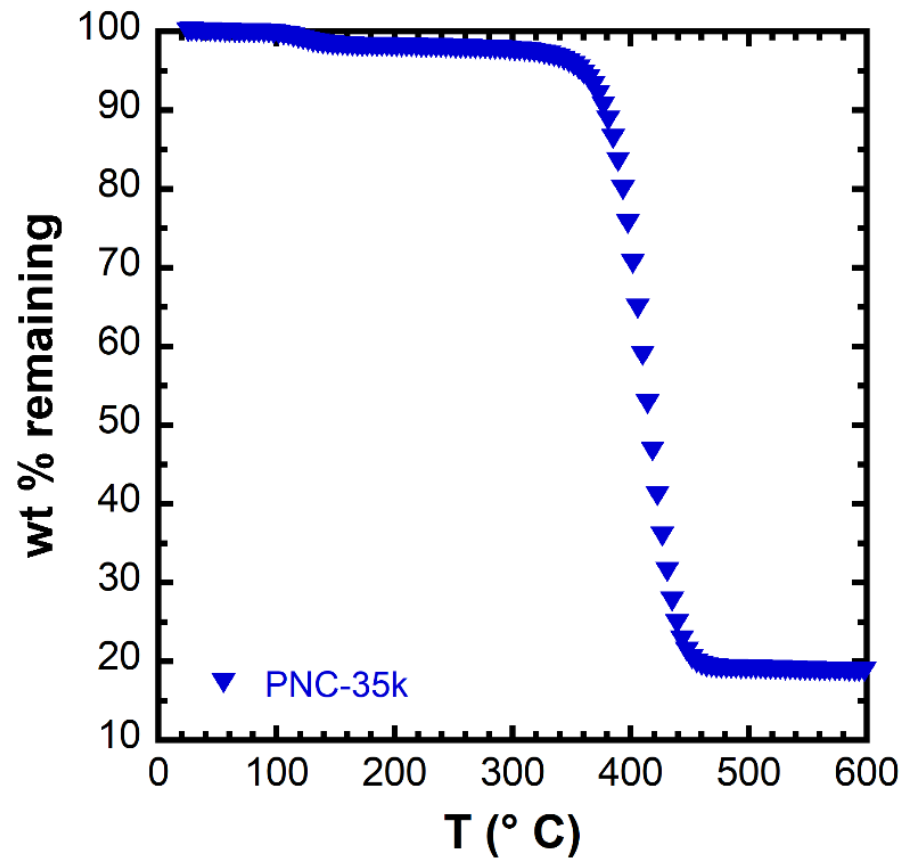




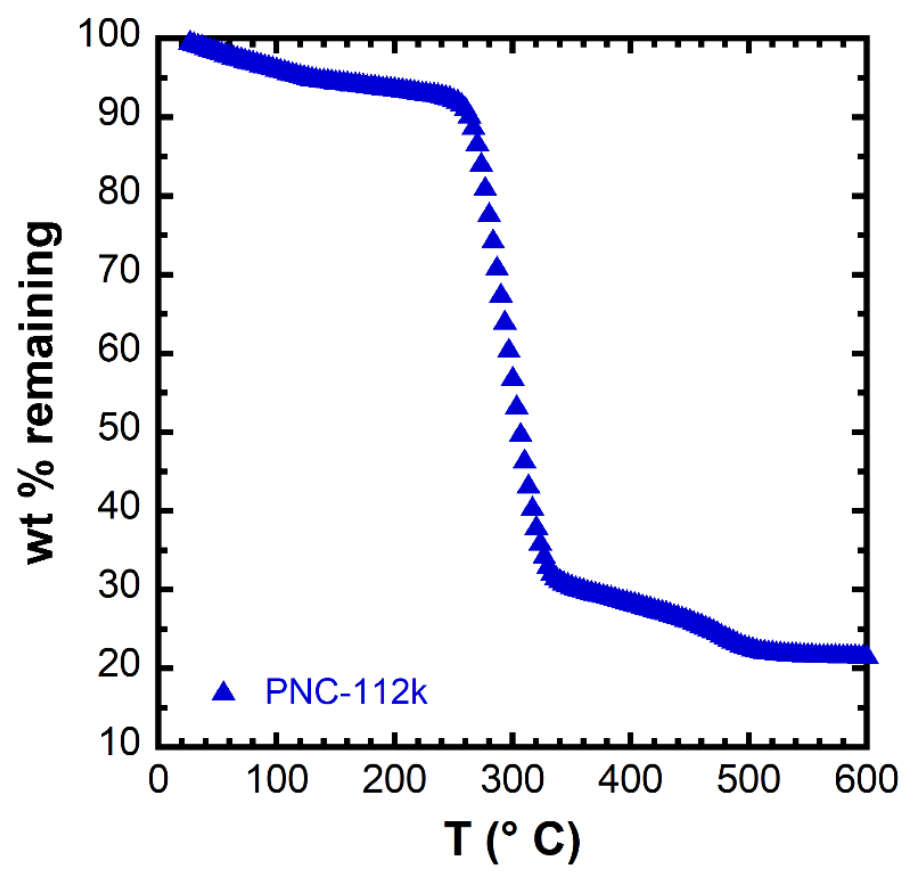

26

27

28

Figure S2: TGA of PNC-112k

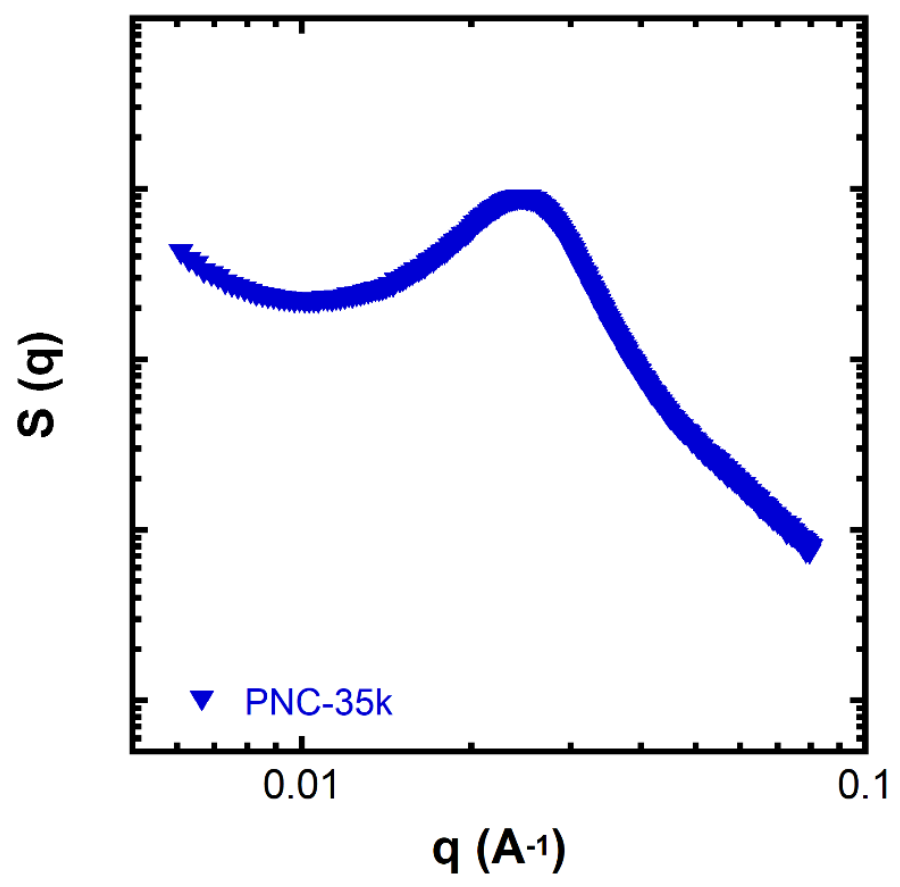

Figure S3: SAXS of PNC-35k. 